RESEARCH REPORT

\title{
Leisure activities and cognitive function in middle age: evidence from the Whitehall II study
}

\author{
A Singh-Manoux, M Richards, M Marmot
}

J Epidemiol Community Health 2003;57:907-913

See end of article for authors' affiliations .....................

Correspondence to: Dr A Singh-Manoux, International Centre for Health and Society, Department of Epidemiology and Public Health, University College London, 1-19 Torrington Place, London WCIE 6BT, UK:

A.Singh-Manoux@ public-health.ucl.ac.uk

Accepted for publication 9 May 2003
Objectives: To test the hypothesis of a positive association, independent of social position, between participation in leisure activities and cognitive function in middle age. The nature of this relation is explored by first classifying leisure activities as entailing high or low cognitive effort, and then classifying them as entailing individual or social activities.

Setting: London based office staff (Whitehall II study) in 20 civil service departments at baseline.

Methods: Data are from the fifth wave of data collection (phase 5) of a prospective cohort study, collected through clinical examination and a self administered questionnaire. Firstly, hierarchical multiple regression was used to examine age and socioeconomic status (SES) adjusted effect of each leisure activity on cognition. Then structural equation models were used to examine the effects of two categories of leisure activities-activities entailing high or low cognitive effort and social or individual activities. All analyses are cross sectional.

Results: There was an age and SES adjusted association between participation in leisure activities and cognitive function. More specifically, leisure activity entailing high cognitive effort or social interaction was associated with better cognitive ability.

Conclusions: Participation in cognitively complex or social leisure activities has an independent association with adult cognition, suggesting that seeking mental stimulation may have a beneficial effect on cognition in middle age.
E vidence of individual differences in the rate of cognitive aging has led to research into factors that might delay cognitive decline in old age. Investigation in this domain is based on the premise that cognitive ability is not "fixed", and that environmental factors play a part in maintaining and augmenting cognition in adulthood. The protective effect of high socioeconomic position has been widely recognised. ${ }^{1-4}$ Increasingly, attention is being paid to lifestyle variables that might be beneficially related to cognitive function. ${ }^{5-8}$ However, relevant research evidence is difficult to interpret as some studies that show a protective effect of lifestyle variables have included SES as a measure of lifestyle. ${ }^{79}$ When SES is used to define an "active" lifestyle an association with cognitive function would simply suggest that high SES individuals seek more stimulating environments leading to the preservation of their mental faculties for longer. It is therefore essential to examine the effect of lifestyle variables while controlling for the effects of SES.

Lifestyle is seen to represent a number of different constructs—-social support, ${ }^{5}$ social network, ${ }^{5}{ }^{8}$ social/leisure activities, ${ }^{5}{ }^{10}{ }^{11}$ physical exercise/sports activity, ${ }^{81}$-and there is some support for a positive association with cognitive function for all of them. In some studies composite indices that combine measures of social network, social support, marital status, and social activities have been used, ${ }^{5}$ making it impossible to identify specific beneficial lifestyle variables. However, it is generally accepted that participation in complex activities is beneficial to maintenance of cognitive ability in adults. ${ }^{42}{ }^{13}$ In this study we first test the hypothesis of a SES adjusted, positive association between participation in leisure activities and cognition. Then we explore the "complexity" hypothesis by classifying leisure activities in two ways: first as requiring either high or low cognitive effort and then as being either individual or social activities. There is already some evidence to show that activities with higher cognitive demand have a more robust association with
Cognition, ${ }^{10}{ }^{14}{ }^{15}$ leading us to expect the same in our sample. Participation in social as compared with individual activities captures the complexity hypothesis in terms of social engagement and the link with cognition will be explored here.

\section{METHOD}

\section{Study population}

The Whitehall II study

The Whitehall II study was established in 1985 as a longitudinal study to examine the socioeconomic gradient in health and disease among 10308 civil servants (6895 men and 3413 women). ${ }^{16}$ All civil servants aged $35-55$ years in 20 London based departments were invited to participate by letter. In total, $73 \%$ of those invited agreed to take part in phase 1 . Response rate at baseline varied by employment grade, being $81 \%$ among the top three employment grade categories and $68 \%$ among the lower three categories. Baseline examination (phase 1) took place during 19851988, and entailed a clinical examination and a self administered questionnaire containing sections on demographic characteristics, health, lifestyle factors, work characteristics, social support, and life events. Clinical examination included measures of blood pressure, anthropometry, biochemical measurements, neuroendocrine function, and subclinical markers of cardiovascular disease. Subsequent phases of data collection have alternated between postal questionnaire alone and postal questionnaire accompanied by a clinical examination. Since baseline five phases of data collection rounds have been completed, with

Abbreviations: $\mathrm{SES}$, socioeconomic status; $\mathrm{CFI}$, comparative fit index; RMSEA, root mean square error of approximation; FIML, full information maximum likelihood 
the most recent phase of data collection (phase 6) completed in 2001. A battery of cognitive tests was introduced to the study midway through phase 3 , consequently cognitive data are available on $40 \%$ of available sample at phase 3 and the entire sample at phase 5 of data collection. Data for the analyses reported here are drawn from phase 5 (1997-1999) as the activity questionnaire was introduced to the study only at phase 5 .

\section{Measurement of socioeconomic status}

Three measures were used to assess SES. These were:

Education, measured as the highest level of education achieved, with the respondent choosing one of 11 categories in the questionnaire. This was regrouped into five standard hierarchical levels: (1) no formal education, (2) lower secondary education, (3) higher secondary education, (4) university degree, (5) higher university degree.

Occupation, assessed via civil service employment grade. All jobs in the civil service have a grade of employment. Employment grade of participants included in this study ranges from grade 1 to grade 6 , with grade 1 representing the highest level and grade 6 the lowest. People in different grades differ with respect to salary, social status and level of responsibility. On 1 January 1987 salaries ranged from $£ 62100$ for grade 1 to $£ 3061$ for grade 6. For analyses presented in this paper employment grade has been recoded so that 6 represents high grade and 1 represents low grade.

Income, assessed via a question asking respondents to pick a category that corresponded most closely with their annual personal income ("amount received annually from salary or wages, or pensions, benefits and allowances before deduction of tax"). There were eight categories, ranging from "less than $£ 9999$ " to "more than $£ 70000$ ". For the purposes of analysis the two highest and the two lowest personal income categories were collapsed to leave six categories. These categories are as follows, $6 \geqslant £ 50000 ; 5=£ 35000-£ 49999$; $4=£ 25000-£ 34$ 999; $3=£ 20000-£ 24$ 999; $2=£ 15000-$ $£ 19$ 999; and $1 \leqslant £ 14999$.

\section{Measurement of cognitive function}

The cognitive test battery consisted of five standard tasks chosen to provide a comprehensive assessment of cognitive function.

Verbal memory test was assessed by a 20 word free recall test of short term memory. Participants were presented with a list of 20 one or two syllable words at two second intervals and were then asked to recall in writing as many of the words in any order within two minutes (maximum possible score $=20$, mean $=6.86, \mathrm{SD}=2.45$ )

The AH $4-\mathrm{I},{ }^{17}$ is composed of a series of 65 items- 32 verbal and 33 mathematical reasoning items of increasing difficulty. This is a test of inductive reasoning that measures the ability to identify patterns and infer principles and rules. Participants had 10 minutes to complete this section (maximum possible score $=65$, mean $=46.45, \mathrm{SD}=11.32$ ).

The Mill Hill Vocabulary test, ${ }^{18}$ assesses knowledge of verbal meaning and encompasses the ability to recognise and comprehend words. We used the test in its multiple format, which consists of a list of 33 stimulus words ordered by increasing difficulty, and six response choices per word ( maximum possible score $=33$, mean $=23.86, \mathrm{SD}=5.26$ ).

Two measures of verbal fluency ${ }^{19}$ phonemic and semantic. Phonemic fluency was assessed via "S" words and semantic fluency via "animal" words. Subjects were asked to recall in writing as many words beginning with " $\mathrm{S}$ " ( mean = 16.83, $\mathrm{SD}=4.45)$ and as many animal names as they could (mean $=16.37, \mathrm{SD}=4.21$ ). One minute was permitted for each test.

\section{Measurement of leisure activities}

Information was collected on 13 leisure activities as part of a larger self administered questionnaire. The frequency with which participants engaged in these activities was measured on a 4 point Likert scale: 0 -never, 1-rarely, 2-monthly, 3-weekly. These activities were grouped in three ways. Firstly, scores on all activities were combined to obtain a "composite index" of participation in leisure activities ( maximum possible score $=39$, mean $=15.44, \mathrm{SD}=4.95$ ). Then, two independent raters classified these activities twice (see table 1). In the first instance activities were classified as either entailing high or low cognitive effort. Activities that could be considered to involve intellectual/developmental activity, cultural activity or require some cognitive effort were categorised as being in the "high cognitive effort" group (seven activities in all, maximum possible score $=21$, mean $=6.94, \mathrm{SD}=2.99$ ). Other activities were classified as requiring "low cognitive effort" (six activities in all, maximum possible score $=18$, mean $=8.48, S D=3.19$ ). The same activities were then classified as being "social activities" ( six activities in all, maximum possible score $=18$, mean $=6.18, \mathrm{SD}=2.98$ ) if they entailed engagement with others, if not they were classified as "individual activities" ( seven activities in all, maximum possible score $=21$, mean $=9.05, \quad S D=3.33$ ). There was no disagreement

Table 1 Age adjusted means on leisure activities for men and women* $†$

\begin{tabular}{|c|c|c|c|c|c|}
\hline & & \multirow[b]{2}{*}{ Leisure activities } & \multirow{2}{*}{$\begin{array}{l}\text { Alternate } \\
\text { classification } \ddagger\end{array}$} & \multirow{2}{*}{$\frac{\text { Men }}{\text { Mean }(95 \% \mathrm{Cl})}$} & \multirow{2}{*}{$\frac{\text { Women }}{\text { Mean }(95 \% \mathrm{Cl})}$} \\
\hline & & & & & \\
\hline \multirow{6}{*}{$\begin{array}{l}\text { Activities } \\
\text { entailing low } \\
\text { cognitive effort }\end{array}$} & 1 & $\begin{array}{l}\text { Household tasks, for example, DIY (do it yourself), maintenance, } \\
\text { decorating }\end{array}$ & 1 & $1.60(1.56$ to 1.63$)$ & 1.64 (1.59 to 1.70$)$ \\
\hline & 2 & $\begin{array}{l}\text { Practical activities, making things with your hands, for example, } \\
\text { pottery, drawing, etc }\end{array}$ & 1 & $0.66(0.62$ to 0.70$)$ & $0.73(0.67$ to 0.78$)$ \\
\hline & 3 & Gardening & I & $2.10(2.06$ to 2.14$)$ & $2.13(2.08$ to 2.19$)$ \\
\hline & 4 & Visiting friends and relatives & $\mathrm{S}$ & $2.15(2.12$ to 2.17$)$ & $2.11(2.07$ to 2.15$)$ \\
\hline & 5 & Going to pubs and social clubs & $\mathrm{s}$ & 1.19 (1.15 to 1.23$)$ & 1.24 (1.18 to 1.29$)$ \\
\hline & 6 & Religious activities/observance & 1 & $0.79(0.75$ to 0.83$)$ & $0.74(0.69$ to 0.80$)$ \\
\hline \multirow{7}{*}{$\begin{array}{l}\text { Activities } \\
\text { entailing high } \\
\text { cognitive effort }\end{array}$} & 7 & Using a home computer for leisure & i & $0.57(0.54$ to 0.60$)$ & $0.61(0.57-0.65)$ \\
\hline & 8 & $\begin{array}{l}\text { Cultural visits to stately homes, galleries, theatres, cinema, or live } \\
\text { music events }\end{array}$ & $\mathrm{S}$ & $1.38(1.35$ to 1.41$)$ & 1.33 (1.29 to 1.37$)$ \\
\hline & 9 & Social indoor games, cards, bingo, chess, etc & $\mathrm{S}$ & $0.49(0.46$ to 0.53$)$ & $0.53(0.48$ to 0.57$)$ \\
\hline & 10 & Individual occupations, for example, reading, listening to music & 1 & $2.80(2.78$ to 2.82$)$ & $2.81(2.78$ to 2.84$)$ \\
\hline & 11 & Positions of office, school governor, councillor, etc & $\mathrm{S}$ & $0.21(0.19$ to 0.23$)$ & $0.21(0.18$ to 0.24$)$ \\
\hline & 12 & Involvement in clubs and organisations, voluntary, or official. & $\mathrm{S}$ & 1.03 (0.99 to 1.07$)$ & $1.04(0.98$ to 1.10$)$ \\
\hline & 13 & Courses and education/evening classes & I & $0.52(0.48$ to 0.55$)$ & $0.49(0.44$ to 0.54$)$ \\
\hline
\end{tabular}

*Response on 4 point Likert scale, 0 -never, 1-rarely, 2-monthly, 3-weekly. †There were no sex differences in participation in leisure activities, $\mathrm{F}$ (13, $5337)=1.51, p=0.11$. fLeisure activities also classified as being individual (I) activities (items 1, 2, 3, 6, 7, 10, 13) or social (S) activities (items $4,5,8,9$, 11,12 ). 


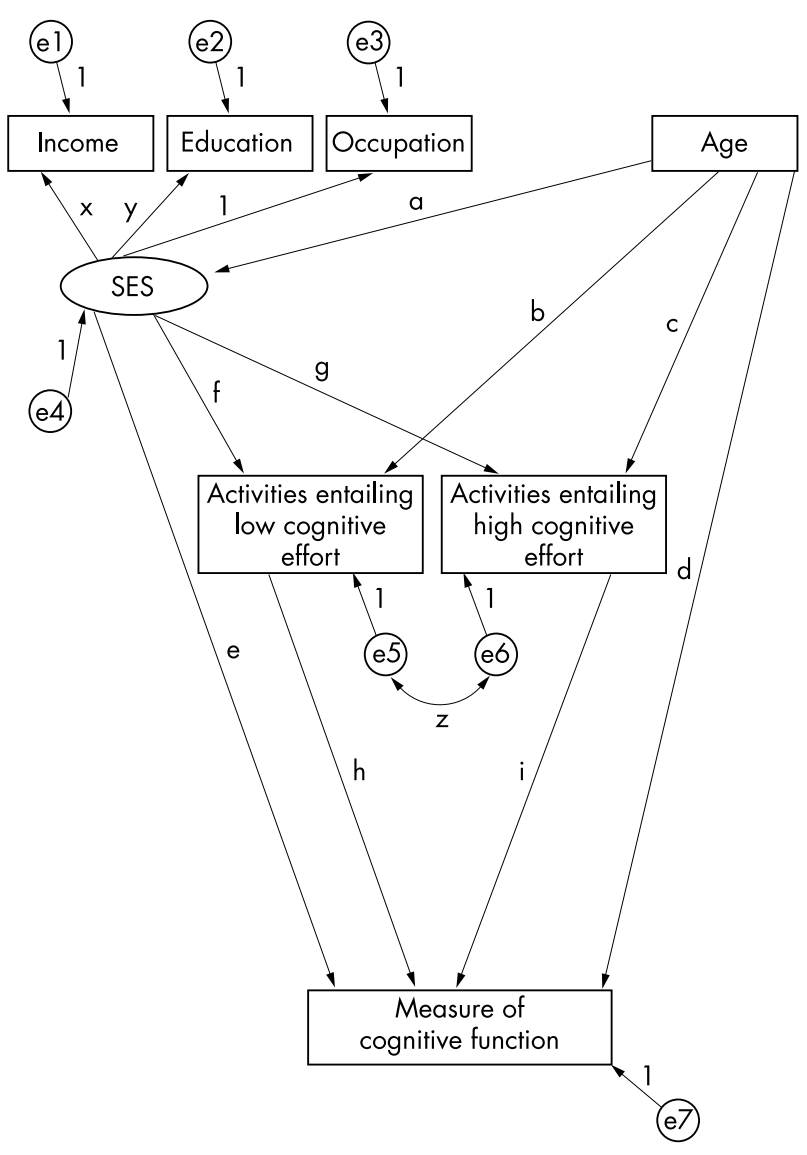

Figure 1 Model representing age and SES adjusted effects of leisure activities on cognitive function. (In the second set of analysis," individual activities" replaces "activities entailing low cognitive effort" and "social activities" replaces "activities entailing high cognitive effort"). All observed variables are in boxes, unobserved variables and error terms (el to e7) are in ellipses. $a, b, c, d, e, f, g$, h, and I represent standardised regression coefficients (see table 4 for results).

between the raters concerning the first system of classification. However, both item 6 and 13 on table 1 were seen to social activities by one of the raters. The final decision on these items was made in consultation with the authors of this paper.

\section{Statistical methods}

The first set of analysis entailed hierarchical multiple regressions with cognitive function tests as outcome variables. The order of entry of the predictor variables was as follows: age, followed by the SES variables and finally the activity variable. The second set of analysis was carried out on the activities categorised first as involving high or low cognitive effort and then as social or individual activities. This analysis was carried out using structural equation modelling (SEM) as it allows estimation of several regression estimates simultaneously. Figure 1 depicts the model used. All observed variables are enclosed in boxes, and unobserved variables in ellipses. The unobserved variables are latent constructs and error terms. Error terms are associated with all endogenous variables and represent measurement error along with effects of variables not measured in the study.

Figure 1 shows the model used to estimate the age and SES adjusted effect of the two types of leisure activities on cognitive function. In all, five models were specified for both classifications of leisure activities, one for each measure of cognitive function. Paths $\underline{a}, \underline{b}, \underline{c}$, and $\underline{d}$ represent the effect of age on SES, activities entailing low cognitive effort (or individual activities), activities entailing high cognitive effort (or social activities) and age on cognitive function, respectively. The effect of SES on cognitive function is assessed through path $\mathrm{e}$, and that on the activities themselves through paths $\underline{f}$ and g. The age and SES adjusted effect of the activities on cognitive function is assessed through paths $\underline{h}$ and $\underline{i}$. The activities entailing high cognitive effort (or social activities) and those entailing low cognitive effort (or individual activities) were allowed to correlate in the model and this relation is denoted by $\underline{z}$.

The analysis was carried out using AMOS version 4.01. ${ }^{20}$ Model fit was assessed using multiple criteria as the $\chi^{2}$ statistic is overly sensitive to model misspecification when the sample sizes are large. We used root mean square error of approximation (RMSEA) and comparative fit index (CFI) to assess model fit. An RMSEA value close to zero and a CFI value close to 1 indicates a good fitting model. ${ }^{21}$ The AMOS program permits maximum likelihood estimation based on incomplete data, known as full information maximum likelihood (FIML). This approach is based on the direct maximisation of the likelihood of all observed data, not just from cases with complete data. FIML is preferable to estimation based on complete data (the listwise deletion approach) as FIML estimates will show less bias and be more reliable than the listwise deletion approach even when data deviate from missing at random and are non-ignorable. ${ }^{22}$ The results were checked using asymptotically distribution free methods (as some of the data are not normally distributed) and similar results to FIML were found.

Sex differences in the model were examined using multigroup analysis in a two step procedure. Firstly, the models were estimated separately for men and women and then the analysis was repeated with the pathways in the two groups constrained to be equal in men and women. Post hoc comparisons in model fit were used to identify which parameters differed significantly between men and women.

\section{Missing data}

The Whitehall II study had a total of 10308 respondents at phase 1 of data collection. The median length of follow up from phase 1 to phase 5 was 11 years, with 355 people dying during this period. Altogether 7830 respondents answered the questionnaire at phase 5 and 6553 attended the clinical examination where cognitive tests were administered. Some 6073 of those attending the clinic did at least one cognitive test, 5380 did them all with non-response here clearly influenced by low cognitive scores. In all, we had complete data on the activities questionnaire and all cognitive function tests on 5352 respondents. With respect to baseline, available data were influenced by age $(p=0.001)$ and employment grade $(p=0.001)$ but not sex $(p=0.61)$. Attrition rate was higher among older respondents and low SES groups.

\section{RESULTS}

Descriptive analyses related to the different leisure activities are presented in table 1 . In this sample gardening, visiting friend/relatives, and reading/listening to music were frequent leisure activities. There were no sex differences in the frequency of participation in leisure activities. Table 2 presents the age and SES adjusted effects of the composite index of leisure activity and subsequently, each activity on different measures of cognitive function. All effects are reported using standardised regression coefficients, also known as "betas" (see table 2). These coefficients are calculated from standardised data and reflect the impact on the outcome variable of a change of one standard deviation in the predictor variables. For example, an increase of one standard deviation in the index of leisure 


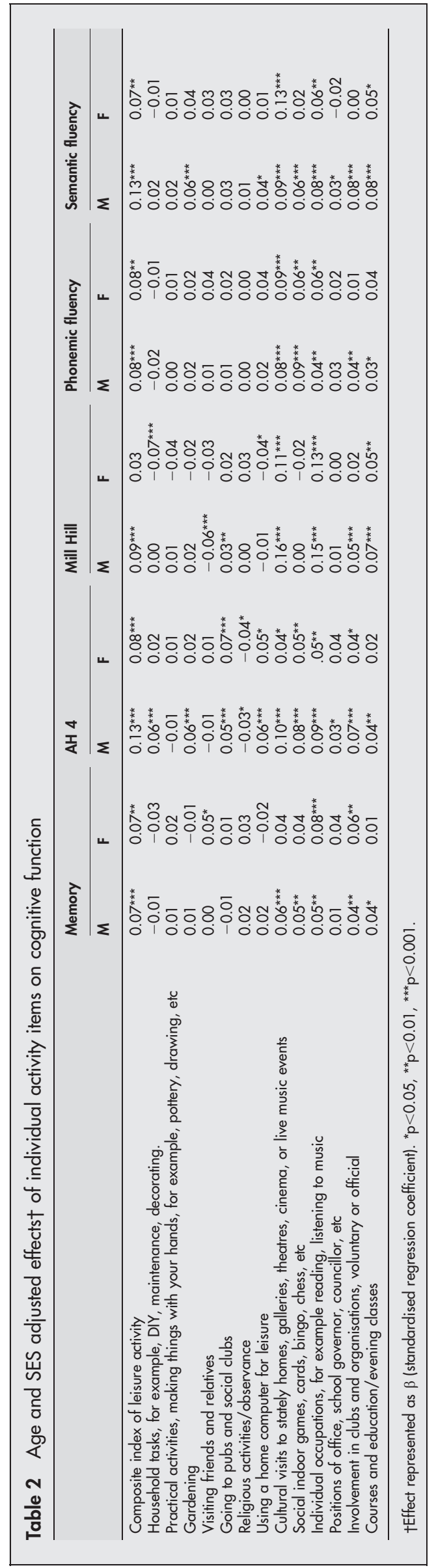

activity is associated with an increase in 0.07 of a standard deviation in memory in men. The advantage of standardised regression coefficient is that it eliminates the problem of dealing with different units of measurement, permitting assessment of the relative importance of predictor variables to be made across different measures of cognitive function.

The composite index of leisure activities shows a positive relation with all measures of cognitive function, with the effect being stronger in men. Activities that show an effect on some measures of cognitive function are gardening, going to pubs and clubs, using a home computer for leisure, and holding voluntary positions of office. Activities more comprehensively associated with cognitive function are cultural visits, social indoor games, reading/listening to music, involvement in voluntary organisations, and participation in evening courses. Subsequent analyses were carried out on the activities grouped in two ways: high or low cognitive effort activities and then social or individual activities.

The correlation between sociodemographic variables, measures of cognitive function and grouped leisure activities is shown in table 3. Age is negatively correlated with all variables except activity variables, indicating that people engage in more leisure activities as they get older. SES variables are predictably related to leisure activities. Occupation has the strongest overall relation with leisure. Education has a stronger relation with high as compared with low cognitive effort activities. All five measures of cognitive function show a stronger relation with activities entailing high cognitive effort compared with those involving low cognitive effort. Social activities also show a stronger relation with measures of cognitive function.

The path estimates a to i depicted in the model in figure 1 are shown in table 4. Goodness of fit statistics indicate that the models were an adequate representation of the data (CFI $=0.99$, RMSEA $=0.08$ for all 5 models). Here again, effects are reported using standardised regression coefficients. Estimates of path a show that older respondents have lower SES. The estimates for paths $\underline{b}$ and $\underline{c}$ show that older respondents also engage more in leisure activities. These results show that older respondents engage more in high cognitive effort and individual leisure activities. In women, there is significantly stronger relation between age and individual activities (path $\underline{b}$ ). Path $\underline{\mathrm{d}}$ shows that the older participants have poorer cognitive function on all measures except the Mill Hill where age had a small protective effect. The estimate for path e reveals that socioeconomic advantage is associated with better cognitive ability. This effect is strongest for AH 4 and Mill Hill, followed by the fluency items and finally verbal memory where SES has a stronger effect in men. SES has a stronger effect on activities entailing high cognitive effort (path g) as compared with those entailing low cognitive effort (path $\mathrm{f}$ ).

Paths $\mathrm{h}$ and $\mathrm{i}$ assess the age and SES adjusted effects of leisure activities on cognitive function. The results indicate that participation in activities qualified by low cognitive effort does not have a positive effect on cognitive function. However, participation in activities involving high cognitive effort has a positive effect on cognitive function, an effect that is independent of the effect of SES. Our results also show sex differences in path $i$, indicating that participation in cognitively challenging àctivities has a significantly stronger effect on cognitive function in men. When these activities were classified as being social or individual activities, social activities were found to have a comprehensive association with cognitive function. Individual activities did show a relation with some measures of cognition, but only in men. 


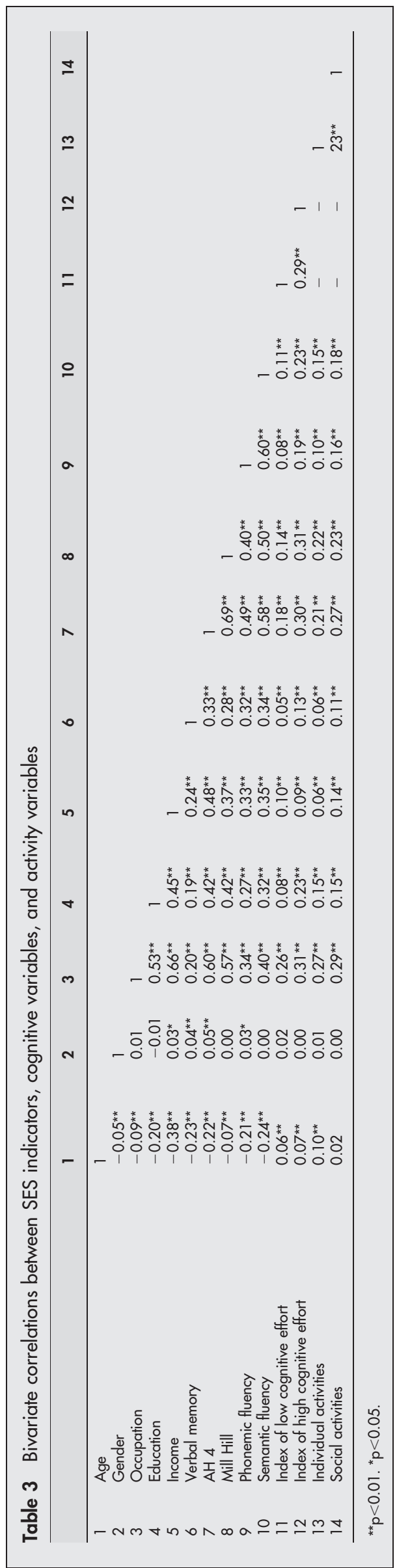

\section{DISCUSSION}

We examined the association between participation in leisure activities and cognitive function in a large cohort study. Cognitive function was assessed comprehensively in this study with measures on memory, verbal fluency, fluid (AH 4) and crystallised intelligence (Mill Hill). The overall "index of participation in leisure activities" was significantly related to cognitive function. Examination of leisure activities, one at a time, shows some activities to have a stronger relation with cognitive function than others. Activities that show a link with cognition entail investment in personal development (cultural visits, individual occupations like reading, courses and evening classes), social engagement (social indoor games) and involvement in the community (involvement in clubs and organisations, voluntary or official).

Separation of leisure activities into low or high cognitive effort categories clearly shows that participation in the latter has a beneficial association with cognitive function. A closer look at the individual effects of the activities that make up the high effort index suggests that not all items in this category have a significant relation with measures of cognitive function. Using a home computer for leisure and occupying positions of office (school governor councillor, etc) have only a limited association with cognitive function. Classification of leisure activities into individual and social activities shows social activities to have a stronger and more consistent relation with cognition. Our results clearly support the hypothesis that social engagement has a positive association with cognition even though the size of the association is weaker than that between cognitively complex activities and cognitive ability.

Studies in this area have not explicated the mechanisms by which leisure activities would have an effect on cognition. This has led different researchers to use different criteria to categorise items. Elwood and colleagues used factor analysis to categorise 18 leisure items into four groups: social, cultural, physical, and intellectual. ${ }^{10}$ Aartsen et al used inter-rater agreement to develop three categories: social, experiential, and developmental. ${ }^{23}$ Other studies have used a composite index of participation in social and leisure activities. ${ }^{24}$ As the association between certain types of leisure activities and cognitive function seems to be robust, attention needs to be paid to underlying mechanisms. We hypothesised that participation in complex activities, both socially complex and cognitively complex, is beneficial as it requires a greater mobilisation of cognitive faculties resulting in their preservation for a longer period. Like education and occupation, participation in demanding leisure activities would augment brain reserve capacity, ${ }^{3425}$ which may offer protection from cognitive decline in old age.

The importance of controlling for SES when examining the association between leisure activities and cognition is clearly demonstrated by the strength of the association between SES and cognition (path e, table 4). Socioeconomic circumstances have been modelled comprehensively in this paper as it is probable that different measures of socioeconomic circumstances have a synergistic effect on cognitive function..$^{26-28}$ The persistence of the association between leisure activities and cognition could be interpreted in two ways:

Engagement in complex leisure augments cognitive function: this interpretation of our results is supported by research on neuronal plasticity in adults, ${ }^{29}$ older people, ${ }^{30}$ and patients with dementia. ${ }^{31}$ However, research on plasticity focuses on acquisition of specific skills as a result of specific training. The research linking high occupational attainment and cognitive function in adult life suggests that the stimulation provided by work helps to maintain cognitive function..$^{27}$ 32-34 It is possible that mental stimulation provided by complex leisure activities has a similar effect. Our results need to be 


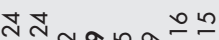

i

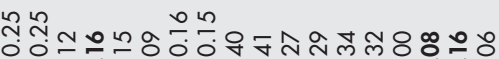

i

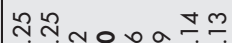

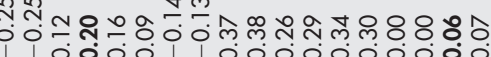

พ พ พ

1

กิ

กั่

3

1 1 000000000001000

言

กิบ

i

สะ

สิกลก

३े 1,000011000000000

.

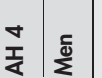

สำ

i

พอ

พิ กิก

३े

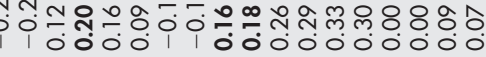

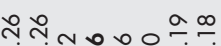

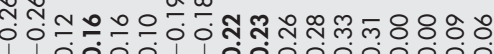
10000110000000000

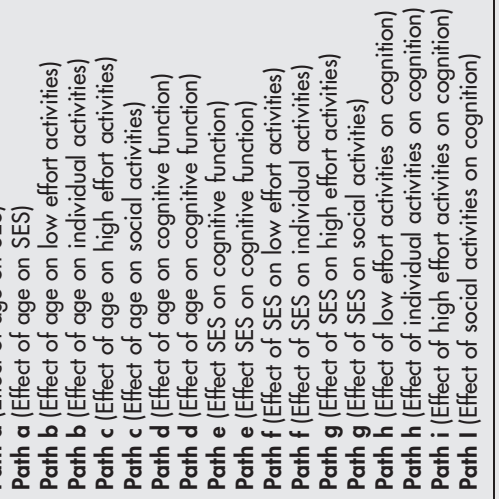

replicated in longitudinal studies in order to show that engagement in complex leisure activities protects against cognitive decline.

Cognitively able people engage in complex leisure activities: this is an equally plausible interpretation of our results. No causal link between participation in leisure activities and cognitive abilities is implied by this interpretation. It is indeed possible that high cognitive ability in people is associated with participation in socially and cognitively demanding leisure activities, irrespective of socioeconomic background. Although there is some evidence to suggest that active leisure is positively associated with cognition in adulthood after adjusting for prior cognition. ${ }^{11}$

Our results also reveal some intriguing sex differences. Although there are no sex differences in frequency of participation in activities, men show a stronger relation between participation in cognitively complex activities and four of the five measures of cognitive function examined here. The composite index was also more strongly associated with cognition in men. Pursuit of individual leisure activities has a positive link with cognition only in men. The results could be interpreted to mean that leisure offers less protection to women or that cognitively able women engage in leisure activities examined here to a lesser extent.

To summarise, the results obtained here show that participation in both socially and cognitively complex leisure activities is associated with cognitive function independently of SES and age in a middle aged cohort. Although the associations are small, the fact that they are independent of SES and age lends them significance. We have identified implied "cognitive effort" and "social engagement" as the critical variables determining the importance of leisure activity to cognition. The critical question that future research needs to address is whether social engagement has a positive association with cognition independently of "cognitive effort" implied in the activity. This will help inform public health advice on the organisation of leisure activities for the elderly population.

The advantage of using SEM as the method of analysis lies in being able to simultaneously model the pattern of relations between variables, even allowing an assessment of the strength of association with the covariates and confounders. Our results suggest that the observed associations between age, activity, and cognition also require further investigation. Older people in this cohort engage more in individual activities, whereas it is the relation between social activities and cognition that is stronger. Older respondents in this sample have poorer cognitive function, but also participate more in leisure activities. It is likely that age will have a stronger negative impact on cognition among people who do

\section{Key points}

- Regular participation in leisure activities has a positive association, independent of age, education, and socioeconomic variables, with cognitive function.

- Leisure activities high in cognitive effort are more strongly related to cognition when compared with low cognitive effort activities.

- Activities high on social engagement are more strongly related to cognition than individual leisure activities.

- Our analyses, showing a positive relation between participation in leisure activities and cognition in middle age, supports the neuronal plasticity hypothesis. 


\section{Policy implications}

- Policy implication from the results reported here relate to public health advice on healthy aging, particularly as life expectancy in the developed world continues to grow. This paper shows that seeking mental and social engagement through leisure activities has a beneficial impact on cognitive ability among middle aged adults. Cognitive ability is directly linked to health outcomes as cognitive impairment in old age is related to functional decline and mortality. This paper contributes to the growing body of evidence on neuronal plasticity in adults, suggesting that what we do as adults helps to maintain and perhaps augment cognitive ability.

not engage in leisure activities making this issue particularly relevant to the low SES, older people who do not engage in leisure activities.

There are some obvious caveats to the conclusions drawn in this study. The results are cross sectional and need to be replicated in a longitudinal study before causal relations can be presumed. Furthermore, results obtained here need to be interpreted in light of the fact that Whitehall II is a study of white collar workers and does not represent the whole socioeconomic range. Our results suggest that participation in leisure is socially patterned, whether leisure activities has the same impact in a more heterogeneous population remains to be investigated.

\section{ACKNOWLEDGEMENTS}

The Whitehall II study has been supported by grants from the Medical Research Council; British Heart Foundation; Health and Safety Executive; Department of Health; National Heart Lung and Blood Institute (HL36310), US, NIH: National Institute on Aging (AG13196), US, NIH; Agency for Health Care Policy Research (HS06516); and the John D and Catherine T MacArthur Foundation Research Networks on Successful Midlife Development and Socioeconomic Status and Health. MM is supported by an MRC Research Professorship. We also thank all participating civil service departments and their welfare, personnel, and establishment officers; the Occupational Health and Safety Agency; the Council of Civil Service Unions; all participating civil servants in the Whitehall II study; and all members of the Whitehall II study team.

\section{Authors' affiliations}

A Singh-Manoux, M Marmot, International Centre for Health and Society, Department of Epidemiology and Public Health, University College London, London, UK

M Richards, MRC National Survey of Health and Development, Department of Epidemiology and Public Health, University College London

\section{REFERENCES}

1 Holland CA, Rabbitt P. The course and causes of cognitive change with advancing age. Rev Clin Gerontol 1991;1:81-96.

2 Jorm AF. The epidemiology of Alzheimer's disease and related disorders. London: Chapman and Hall Medical, 1990.

3 Katzman R. Education and the prevalence of dementia and Alzheimer's disease. Neurology 1993;3:13-20.
4 Orrell M Sahakian B. Education and dementia. BMJ 1995:10:951-2.

5 Bassuk SS, Glass TA, Berkman LF. Social disengagement and incident cognitive decline in community-dwelling elderly persons. Ann Intern Med 1999;131:165-73.

6 Christensen $\mathbf{H}$, Korten A, Jorm AF, et al. Activity levels and cognitive functioning in an elderly community sample. Age Ageing 1996;25:72-80.

7 Gribbin K, Schaie KW, Parham IA. Complexity of lifestyle and maintenance of intellectual abilities. Journal of Social Issues 1980;36:47-61.

8 Stevens FCJ, Kaplan CD, Ponds RWHM, et al. How ageing and social factors affect memory. Age Ageing 1999;28:379-84.

9 Gold DP, Andres D, Etezadi J, et al. Structural equation model of intellectual change and continuity and predictors of intelligence in older men. Psychol Aging 1995; 10:294-303.

10 Elwood PC, Gallacher JEJ, Hopkinson CA, et al. Smoking, drinking, and other life style factors and cognitive function in men in the Caerphilly cohort. $J$ Epidemiol Community Health 1999;53:9-14.

11 Richards M, Hardy R, Wadsworth MEJ. Does active leisure protect cognition? Evidence from a national birth cohort. Soc Sci Med 2003;56:785-92.

12 Schaie KW. Intellectual development in adulthood: the Seattle longitudinal study. New York: Cambridge University Press, 1996.

13 Schooler C. Psychological effects of complex environments during the lifespan: a review and theory. In: Schooler C, Schaie KW, eds. Cognitive functioning and social structure over the life course. Norwood, NJ: Albex, 1987:24-49.

14 Hultsch DF, Hammer M, Small BJ. Age differences in cognitive performance in later life: relationships to self-reported health and activity life style. J Gerontol B Psychol Sci Soc Sci 1993;48:1-11.

15 Hultsch DF, Hertzog C, Small BJ, et al. Use it or lose it: engaged lifestyle as a buffer of cognitive decline in aging. Psychol Aging 1999;14:245-63.

16 Marmot MG, Davey Smith G, Stansfeld S, et al. Health inequalities among British civil servants: the Whitehall II study. Lancet 1991;337:1387-93.

17 Heim AW. AH 4 group test of general intelligence ASE. Windsor, UK: NFERNelson, 1970

18 Raven JC. Guide to using the Mill Hill vocabulary scale with progressive matrices. London: H K Lewis, 1965.

19 Borkowski JG, Benton AL, Spreen O. Word fluency and brain damage. Neuropsychologica 1967;5:135-40.

20 Arbuckle JL, Wothke W. Amos 4.0 user's guide. Chicago: Small Waters, 1995.

21 Mueller RO. Basic principles of structural equation modeling. New York: Springer Verlage, 1996

22 Arbuckle JL. Full-information estimation in the presence of incomplete data. In: Marcoulides GA, Schumacker RE, eds. Advances structural equation modeling techniques. Mahwah, NJ: Lawrence Erlbaum, 1996:243-77.

23 Aartsen MJ, Smits CHM, van Tilburg T, et al. Activity in older adults: cause or consequence of cognitive functioning? A longitudinal study on everyday activities and cognitive performance in older adults. J Gerontol B Psychol Sci Soc Sci 2002;57:153-62.

24 Fabrigoule C, Letenneur L, Dartigues JF, et al. Social and leisure activities and risk of dementia: a prospective longitudinal study. J Am Geriatr Soc 1995;43:485-90.

25 Swab DF. Brain ageing and Alzheimer's disease, "wear and tear" versus "use it or lose it". Neurobiol Aging 1991;12:317-24.

26 Schmand B, Smit JH, Geerings Ml, et al. The effects of intelligence and education on the development of dementia. A test of the brain reserve hypothesis. Psychol Med 1997;27:1337-44.

27 Stern Y, Gurland B, Tatemichi TK, et al. Influence of education and occupation on the incidence of Alzheimer's disease. JAMA 1994:271:1004-10.

28 Wight RG, Aneshensel CS, Seeman TE. Educational attainment, continued learning experience, and cognitive function among older men. J Aging Health 2002;14:211-36

29 Maguire EA, Gadian DG, Johnsrude IS, et al. Navigation-related structural change in the hippocampi of taxi drivers. Proc Natl Acad Sci USA 2000;97:4398-403.

30 Baltes PB, Willis SL. Plasticity and enhancement of intellectual functioning in olde age: Penn State's Adult Development and Enrichment Project (ADEPT). In: Craik FIM, Trehub S, eds. Aging and cognitive processes. New York: Plenum Press, 1982:353-89.

31 Koh K, Ray R, Lee J, et al. Dementia in elderly patients: can the 3R mental stimulation programme improve mental status? Age Ageing 1994;23:195-9.

32 Bonaiuto S, Rocca WA, Lippi A, et al. Education and occupation as risk factors for dementia: a population-based case-control study. Neuroepidemiology 1995;14:101-9.

33 Callahan CM, Hall KS, Hui SL, et al. Relationship of age, education, and occupation with dementia among a community-based sample of African Americans. Arch Neurol 1996;53:134-40.

34 Dartigues JF, Gagnon M, Letenneur L, et al. Principal lifetime occupation and cognitive impairment in a French elderly cohort (Paquid). Am J Epidemiol 1992;135:981-8. 